\title{
Review
}

\section{Defensins and innate host defence of the gastrointestinal tract}

The challenge of host defence in the digestive tract When viewed from the perspective of host defence, the mammalian digestive tract presents many challenges. At the outset food contains various micro-organisms that could thrive in the rich growth medium of digested nutrients. Because a large surface area is required for the absorption of nutrients, there are abundant potential sites for microbial attachment and invasion in the long digestive tube with its many folds, villi and microvilli. The requirements of efficient nutrient absorption also place limits on the barrier components of host defence. Indeed, unlike the skin, vaginal epithelium or oral mucosa, intestinal mucosa is comprised of only a single layer of epithelial cells. This delicate barrier is further threatened by the effects of acid, bile salts, and hydrolytic enzymes required for digestion. Although some of these molecules are toxic to microbes, and hence may help to control microbial proliferation and survival, these agents may also subtly damage the mucosa and compromise its barrier functions. The potential for cumulative damage may explain why this epithelium is rapidly and continually replaced throughout the lifetime of mammals. As a result of the need for epithelial renewal, stem cell proliferation and differentiation are critical for normal function of the gastrointestinal tract. Damage to, or parasitisation of stem cells would have severe consequences for the maintenance of the normal digestive epithelium.

A continuous microbial threat is also posed by a wide array of colonising microbes throughout the gut, with especially large numbers in the mouth and colon. Infectious complications that often follow treatment with antibiotics suggest that colonising symbionts contribute to host defence against pathogens. Yet, in the absence of effective defence mechanisms, even symbiotic microbes can multiply rapidly and overwhelm the mammalian host. Despite the presence of microbes, normal digestive tract surfaces generally show little evidence of inflammation, the coordinated pattern of vasodilatation, leucocyte recruitment and transudation of leucocytes and plasma that constitutes a common response of many tissues to microbes. In the absence of inflammation, steady state defence in this organ system must rely on other broadly effective mechanisms. This review will focus on one such mech-

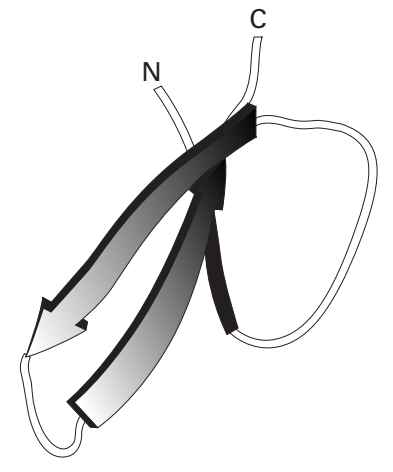

$\alpha$-defensin

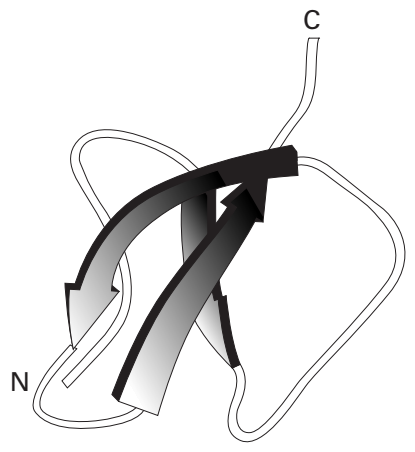

$\beta$-defensin
Figure 1 Structure of $\alpha$-and $\beta$-defensins. Figure reproduced from reference 12 with permission. anism, the production of defensins, a group of antimicrobial peptides that contribute to innate immune defences in the gastrointestinal tract and other body surfaces.

\section{Antimicrobial peptides}

Antimicrobial peptides (arbitrarily defined as $<100$ amino acids in size) are found abundantly in many host defence settings, from plant seeds and arthropod haemolymph to human neutrophils and epithelia. ${ }^{1-5}$ Unlike many other antibiotics in nature, which are produced by specialised metabolic pathways, antimicrobial peptides are encoded by genes and produced by conventional transcription and translation. The various peptides are structurally diverse and range from simple, $\alpha$-helical linear molecules to molecules with $\beta$-sheet conformation and multiple disulphide linkages, but in general have antimicrobial activity against a broad range of microbes at micromolar concentrations. Most of these peptides are cationic and amphipathic, features that confer affinity for microbial membranes rich in anionic phospholipids, and a degree of protection for host cell membranes that contain neutral phospholipids and cholesterol. Proposed mechanisms of microbicidal activity for the various peptides include pore formation and membrane depolarisation, disruption of bacterial energy metabolism and interference with biosynthetic pathways.

Evidence for the specific roles of antimicrobial peptides in host defence has been provided by experiments that assess the impact of ablation or augmentation of antimicrobial peptide production. Augmentation of antimicrobial peptide production in plants increases their resistance to plant pathogens, ${ }^{6-8}$ whereas ablation of the pathways that induce the production of antifungal peptide drosomycin in Drosophila dramatically reduces survival after fungal infections. ${ }^{9}$ Analogous experiments in transgenic mice are a subject of intense effort in several laboratories. The experimental design may be complicated by the multiplicity of antimicrobial peptides and redundancies in the innate and adaptive immune systems.

In mammals, defensins are one of the major families of antimicrobial peptides. ${ }^{5}$ Characteristically, these peptides are 30-42 amino acids in length, have a cationic charge, a predominance of $\beta$-sheet conformation, and contain six cysteines that participate in three intramolecular disulphide bonds. Based on the spatial distribution of the cystine linkages, the mammalian defensins may be classified into two major groups termed $\alpha$ - and $\beta$-defensins. In $\alpha$-defensins, invariant disulphide bonds form between cysteines $\mathrm{C} 1-\mathrm{C} 6, \mathrm{C} 2-\mathrm{C} 4$, and $\mathrm{C} 3-\mathrm{C} 5 .{ }^{10}$ In $\beta$-defensins, the pairing occurs between $\mathrm{C} 1-\mathrm{C} 5, \mathrm{C} 2-\mathrm{C} 4$, and $\mathrm{C} 3-\mathrm{C} 6 .^{11}$ Although their disulphide linkages differ, the three dimensional structure of both groups of peptides is very similar (fig 1). In humans, the genes that encode $\alpha$ - and $\beta$-defensins are clustered in a segment a few hundred kilobases long of the short arm of chromosome 8 (8p23), ${ }^{13-15}$ and the corresponding homologous genes are similarly clustered in the rodent genome. ${ }^{16-20}$

The $\alpha$-defensins were among the first antimicrobial peptides to be discovered and are major constituents of the

Abbreviation used in this review: NEC, necrotising enterocolitis. 

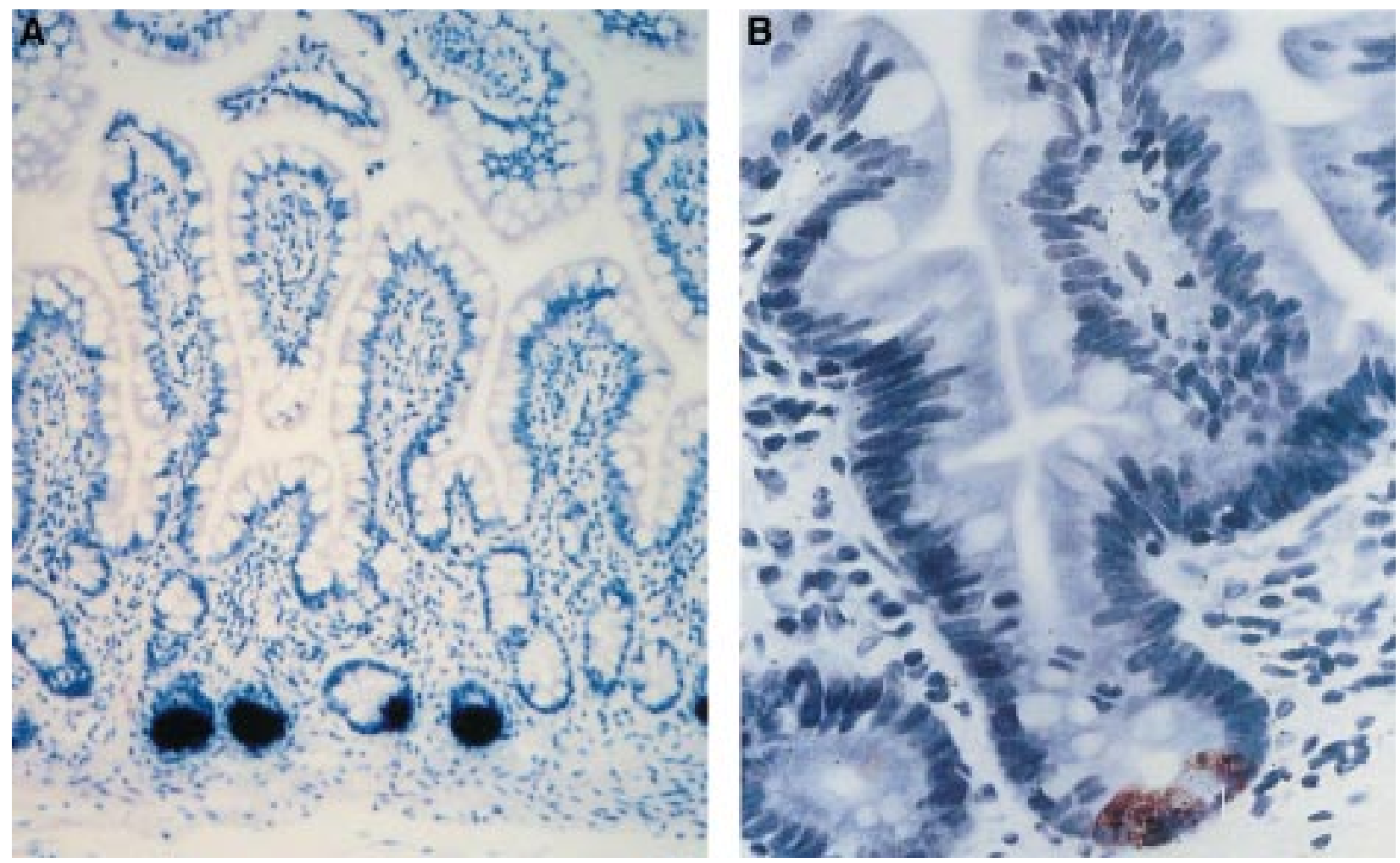

Figure 2 Localisation of HD-5 mRNA (A, aggregates of abundant black silver grains) and peptide (B, brown peroxidase product) to Paneth cells in the crypts of Lieberkühn. Figures reproduced from references 28 and 46, respectively, with permission.

primary granules of mammalian granulocytes. ${ }^{21-23}$ In humans, the $\alpha$-defensins HNP 1-4 account for roughly 5\% of the total cellular protein of neutrophils. Defensin granule concentrations are probably in excess of $10 \mathrm{mg} / \mathrm{ml}$ and upon fusion of primary granules with a phagosome, these defensins are delivered to the engulfed micro-organism with little dilution. ${ }^{23}$ Other $\alpha$-defensins are abundantly expressed in Paneth cells of the small intestinal crypts. ${ }^{24}{ }^{25}$ In humans, two such Paneth cell $\alpha$-defensins have been identified, HD-5 and -6. Recently, the non-haematopoietic $\alpha$-defensin HD- 5 has also been detected in epithelial cells of the genital tract. ${ }^{26}$ Analysis of $\alpha$-defensin gene structure in several species reveals that all haematopoietic $\alpha$-defensin genes have three exons, but that the epithelial $\alpha$-defensin genes have two.

The $\beta$-defensins were discovered in cattle as antimicrobial peptides of airway epithelial cells. ${ }^{27}$ Since then, expression of $\beta$-defensins in many other epithelial cell types and other species has been reported. ${ }^{28}$ Along the alimentary tract, $\beta$-defensins have been found in the gingival epithelia, the tongue and the colon. ${ }^{29-32}$ Two human $\beta$-defensins have been identified, HBD-1 and -2 , with peptides (or transcripts) found in the kidney, skin, pancreas, gingiva, salivary gland, cornea, and airway epithelium. ${ }^{33-36}$ Similar $\beta$-defensins are also expressed in the granulocytes of some vertebrates, including cattle and other ruminants and some avian species. $^{37}$ Like the epithelial $\alpha$-defensins, all $\beta$-defensin genes characterised so far have two exons. ${ }^{28}$

\section{Defensins in small intestinal Paneth cells}

Initially, $\alpha$-defensin genes expressed in Paneth cells of mice were detected as an abundant class of developmentally regulated mRNA. ${ }^{38}$ Human Paneth cell defensin genes were later identified by their sequence similarity to myeloid defensins. ${ }^{39}{ }^{40}$ In mice, there is evidence for the expression of 19 or more (highly similar) defensin genes in the small intestine, ${ }^{41}$ whereas only two human defensins, HD-5 and
-6 have been found at this site following extensive molecular searches. ${ }^{42}$ In mice, cryptdin-1 and cryptdin- 5 mRNA content is equivalent in duodenum, jejunum, and ileum. ${ }^{43}$ In contrast, cryptdin- $4 \mathrm{mRNA}$ is absent or present at very low levels in proximal small bowel, increasing to maximal levels in the distal ileum. In humans, HD-5 and -6 mRNA seem to be coordinately expressed in Paneth cells at a ratio of about $4: 1$. Mature enteric $\alpha$-defensin peptides, also termed cryptdins, have been isolated from the murine small bowel. ${ }^{24} 41445$ Similar attempts to isolate human peptides systematically from intestinal tissue and lumen are currently underway (see later). One isoform of HD-5 (64-94) was prepared recombinantly using a baculovirus/ insect cell expression system ${ }^{46}{ }^{47}$ and has been used to initiate functional studies of this peptide.

Paneth cells are granulated secretory epithelial cells residing in the bases of the crypts of Lieberkühn. Immunohistochemical studies have localised $\alpha$-defensins to apical granules in these cells (fig 2). ${ }^{24}{ }^{46}$ In addition to defensins, their granules contain additional antimicrobial molecules, including lysozyme and sPLA2. ${ }^{48} 49$ Paneth cell granules are released to the luminal mucosal surface consistent with their proposed functions in the crypt lumen. Both intraluminal bacteria and lipopolysaccharide can stimulate this Paneth cell secretion, ${ }^{50}$ as can cholinergic agonists. ${ }^{48}$ The secretion is inhibited by atropine, a muscarinic antagonist. ${ }^{51}$ Paneth cell distribution is generally limited to the small intestine. Paneth cell hyperplasia and metaplasia can be seen in chronic inflammation associated with Barrett's oesophagus, gastritis, carcinoma, Crohn's disease, and ulcerative colitis. ${ }^{52} 53$

Ontologically, Paneth cell differentiation occurs during crypt morphogenesis. Subsequently, Paneth cells differentiate from stem cells that migrate downwards in the crypt. $^{5455}$ Tissue specific expression of Paneth cell defensins is, at least in part, transcriptionally regulated. Analysis of lines of transgenic mice carrying 6.5 kilobases 
of 5'-flanking sequence of the cryptdin-2 gene fused with a human growth hormone reporter gene show expression of the reporter protein in Paneth cells only. ${ }^{54}$ Transgenic mice carrying the HD-5 gene, including 1.4 kilobases of 5'-flanking sequence, express the peptide in Paneth cells in the same developmental sequence as the endogenous mouse genes (Salzman N, Bevins CL, and Huttner KM. Abstract 132/E-53 American Society of Microbiology. New Orleans, 1996). Thus, the 5'-flanking regions of the enteric $\alpha$-defensin genes seem to be sufficient for direct expression in Paneth cells.

\section{Post-translational modifications of defensins}

The main post-translational modifications of defensin peptides are (a) formation of three intramolecular disulphide bonds ${ }^{10} 11$ and $(b)$ proteolytic processing of the $\mathrm{NH}_{2}$-terminus to yield the mature peptide. ${ }^{56}$ In addition, in some defensin peptides the $\mathrm{NH}_{2}$-terminal glutamine is converted to a pyroglutamate residue. ${ }^{29} 37$

Studies of post-translational processing of defensins have focused on human neutrophil $\alpha$-defensins. ${ }^{57-61}$ The human neutrophil peptides are synthesised as 93-94 amino acid prepropeptides that contain N-terminal endoplasmic reticulum targeting (signal) peptides, acidic propeptide segments of approximately 40 amino acids, and a mature peptide at the C-terminus. The defensin precursors are initially cleaved to produce intermediates of 75 and 56 amino acids and subsequently stored in granules almost entirely as fully processed mature peptides (29-30 amino acids). ${ }^{58}$ The acidic propeptide segment may be important for neutralisation, processing, and/or folding of the cationic C-terminal defensin peptide. ${ }^{6061}$

The post-translational processing of epithelial $\alpha$-defensins has not yet been systematically investigated, but may be a key regulatory step in the generation of active Paneth cell $\alpha$-defensins. Isolation and characterisation of HD-5 peptides in human specimens have revealed an unexpected complexity in the $\mathrm{N}$-terminally processed forms of this peptide. ${ }^{62}$ In initial studies of ileal tissue, at least three isoforms were detected by using western blot analysis. Two forms were characterised chemically and corresponded to amino acids $23-94$ and $29-94 .^{62}$ The detection of these larger forms suggests that human Paneth cells, in contrast to neutrophils, may store $\alpha$-defensins as propeptides. These propeptides would then be predicted to be processed to mature peptides either during or after exocytic secretion. The study of HD-5 in a different biological context has detected shorter extracellular forms of this peptide. The surgical construction of neobladders from ileal tissue provides an opportunity to isolate Paneth cell products from voided urine. In neobladder urine, three major forms were characterised chemically, representing amino acids 36-94, 56-94, and 63-94. ${ }^{62}$ The shortest form (63-94) is similar to the mature recombinant HD-5 peptide (amino acids 64-94), which has broad spectrum antimicrobial activity. ${ }^{47}$ For epithelial $\beta$-defensins, generation of forms with variable $\mathrm{N}$-termini was also observed with renal human $\beta$-defensin-1 released into voided urine. ${ }^{36}$

\section{Defensin activities}

Paneth cell $\alpha$-defensins show microbicidal activity against a variety of microbes. Recombinant human Paneth cell HD-5 (64-94) is active against Listeria monocytogenes, Escherichia coli, Salmonella typhimurium, and also against the fungus Candida albicans. ${ }^{47}$ The recombinant HD-5 peptide retains activity even in presence of physiological concentrations of trypsin, evidence that this peptide could function within the hostile environment of the intestinal lumen. ${ }^{47}$ The activities of the natural isoforms of HD-5 recently identified in human small intestine tissues and from ileal neobladder urine have still to be thoroughly investigated.

More extensive structure-function studies have been possible for the mouse Paneth cell $\alpha$-defensins. Of the mouse cryptdins, cryptdin -4 is the most cationic and has the greatest antibacterial activity. ${ }^{41}$ Mouse cryptdins 1, 2, 3, and 6 differ from each other in sequence only by one to four amino acids, yet these peptides have distinct in vitro activities. For example, cryptdin-2, which differs from cryptdin- 3 only by a substitution of threonine at position 10 for lysine, was not bactericidal for $E$ coli, but cryptdin-3 had potent activity. However, with respect to the sensitivity of Giardia lamblia trophozoites, cryptdins-2 and -3 were highly active, whereas cryptdins -1 and -6 had little or no effect on trophozoite survival. ${ }^{63}$ This further supports the notion that apparently subtle aspects of primary structure are important for the biological activity of the defensins. A systematic analysis of the effects of amino acid substitutions on antimicrobial activity against a variety of micro-organisms may uncover important structurefunction relations that could have implications for the design of synthetic antibiotics.

In addition to antimicrobial activity, certain defensins have exerted remarkable effects on host cells. ${ }^{64-67}$ When applied to the apical surfaces of T84 cells, cryptdin- 2 and -3 induce chloride secretion. ${ }^{68}$ Although not a feature of all defensins, such a secretory response induced by microbial entry into the crypt could contribute to host defence by "flushing out" the crypt. Certain other defensins also display chemotactic activity for $\mathrm{T}$ lymphocytes ${ }^{66}$ and other immune cells and may serve as a link between innate and adaptive immunity. ${ }^{69}$

\section{Genetic ablation of Paneth cells}

Introducing artificial transgenes consisting of a cell-typespecific promoter and a region encoding a cytotoxic protein can ablate specific cell lineages during development. This strategy has lead to valuable insights into the function of specific cell populations. Paneth cell deficiency ${ }^{70}$ was induced in mice by placing the 5 '-flanking region of the mouse cryptdin-2 gene upstream of an attenuated diphtheria toxin A fragment coding sequence. In these transgenic mouse lines, roughly $95 \%$ of Paneth cells were eliminated and apparently undifferentiated crypt columnar cells occupied the Paneth cell deficient crypts. In the crypts of these mice maintained in a barrier facility there was no evidence of colonisation by commensal gut microflora as detected by silver staining. ${ }^{70}$ These data suggest that Paneth cell factors may not be required to prevent colonisation of the small intestinal crypt by commensal flora, or that the remaining $5 \%$ of the Paneth cells and other factors can keep the crypt germ-free in otherwise healthy mice. Also, in the absence Paneth cells, it is possible that the epithelium continues to express Paneth cell genes or that other antimicrobial factors are able to compensate for Paneth cell loss. It will be of great interest to test the response of the gut epithelium of these transgenic mice to pathogenic bacterial challenges.

\section{Upregulation of HD-5 and HD-6 mRNA in necrotising enterocolitis}

Necrotising enterocolitis (NEC) is a common, often devastating complication of uncertain aetiology in premature infants and is characterised by intestinal necrosis with haemorrhage and mucosal oedema. ${ }^{71}{ }^{72}$ In cases of NEC, the levels of HD-5 and -6 mRNA expression per Paneth cell are increased threefold over that observed in controls. ${ }^{73}$ This suggests that a mediator produced in the course of 


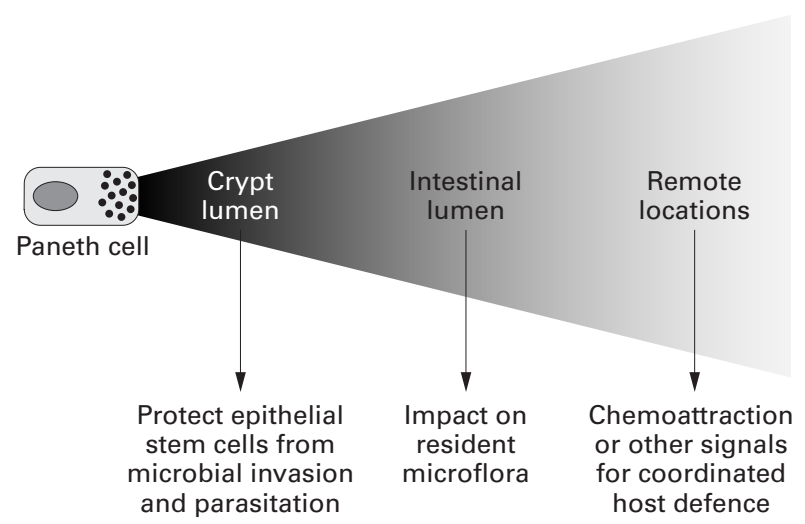

Figure 3 A hypothesis for the role of Paneth cell defensins in intestinal host defence. See text for details.

NEC can induce defensin expression. In addition, the number of Paneth cells is increased about twofold in the NEC specimens compared with controls, suggesting that the disease process promotes Paneth cell hyperplasia. ${ }^{73}$ Interestingly, the intracellular concentration of HD-5 peptide as detected by immunohistochemistry seemed to be unchanged despite an increase in HD-5 mRNA in the NEC samples. One interpretation of these observations is that the defensin peptides are secreted at an increased rate in response to the ongoing disease process.

\section{The role of defensins in intestinal host defence: a hypothesis}

The location of defensin secreting Paneth cells at the bottom of a long narrow crypt adjacent to the mitotic stem cells suggests that defensins act at a high local concentration soon after secretion, and that the object of their activity is the protection of the epithelial stem/progenitor cells of the small intestine (fig 3). If Paneth cells contain as much defensin peptide as neutrophils do, the concentration of defensins at the base of the crypt could reach millimolar levels. In view of the well documented antimicrobial activity of many defensins, it seems reasonable to propose that the function of Paneth cells and their defensins is the protection of the crypt and its stem cells from microbial invasion and parasitisation. It is also possible that the more dilute secretions (perhaps in the micromolar range) that reach the intestinal lumen still contain sufficient activity to influence the resident flora. Finally, at even more remote locations from the site of secretion, very dilute (nanomolar) secretions could function as chemoattractants or provide other signals for host defence cells (lymphocytes, monocytes, dendritic cells).

\section{Future perspectives}

Recent discoveries have helped focus attention on the important contributions of innate immune mechanisms in mammalian host defence. Among the mechanisms of innate immunity in the gastrointestinal tract, epithelial secretion of antimicrobial defensins seems to be particularly well developed in the Paneth cells of the crypts of Lieberkühn. The structure-function relations, biological activities and regulation of Paneth cell defensins are productive areas for further investigations. As antimicrobial peptides have been found in the stomach and the colon of other vertebrates, it is likely that as yet unidentified human antimicrobial proteins and peptides are awaiting discovery in the many epithelial cell types of the digestive tract. It will be interesting to learn how the altered expression of defensins and other antimicrobial peptides, related to genetic deficiencies, developmental immaturity, chronic inflammation or concurrent systemic disease, impacts on innate host defence. Furthermore, in addition to their antimicrobial function antimicrobial peptides may provide important links between the innate and adaptive immune systems by receptor mediated signalling to lymphocytes or other host cells. A better understanding of innate host defence mechanisms may lead to therapeutic strategies that augment the effectiveness of host defence in the digestive tract.

The authors are supported in part by grants from the National Institutes of Health AI32234, AI32738, AI40248 and HL46809.

C L BEVINS

Department of Immunology,

Gastroenterology and Colorectal Surgery,

Lerner Research Institute,

The Cleveland Clinic Foundation,

Cleveland, $\mathrm{OH}$ 44195, USA

E MARTIN-PORTER

T GANZ

Department of Medicine and

The Will Rogers Institute for Pulmonary Research,

University of California School of Medicine,

Los Angeles, CA 90095, USA

Correspondence to: Charles L Bevins, MD, PhD, Research Institute/NB30,

The Cleveland Clinic Foundation, 9500 Euclid Avenue, Cleveland, OH

44195, USA. Email: bevinsc@ccf.org

1 Zasloff M. Antibiotics peptides as mediators of innate immunity. Curr Opin

Immunol 1992;4:3-7.
2 Boman HG. Peptide antibiotics and their role in innate immunity. Annu Rev Immunol 1995;13:61-92.

3 Martin E, Ganz T, Lehrer RI. Defensins and other endogenous peptide antibiotics of vertebrates. F Leuk Biol 1995;58:128-36.

4 Hancock REW, Falla T, Brown M. Cationic bactericidal peptides. Adv Hancock REW, Falla T, Brown
Microb Physiol 1995;37:135-75.

Microb Physiol 1995;37:135-75.
5 Lehrer RI, Bevins CL, Ganz T. Defensins and other antimicrobial peptides. Lehrer RI, Bevins CL, Ganz T. Defensins and other antimicrobial peptides.
In: Ogra PL, Mestecky J, Lamm ME, Strober WM, Bienstock J, eds. Mucosal immunology. 2nd ed. New York: Academic Press, 1998:89-99.

6 Epple P, Apel K, Bohlmann H. Overexpression of an endogenous thionin enhances resistance of Arabidopsis against Fusarium oxysporum. Plant Cell 1997;9:509-20.

7 Fritig B, Heitz T, Legrand M. Antimicrobial proteins in induced plant defense. Curr Opin Immunol 1998;10:16-22.

8 Ohshima M, Mitsuhara I, Okamoto M, et al. Enhanced resistance to bacterial diseases of transgenic tobacco plants overexpressing sarcotoxin IA, a bactericidal peptide of insect. F Biochem (Tokyo) 1999;125:431-5.

9 Lemaitre B, Nicolas E, Michaut L, et al. The dorsoventral regulatory gene cassette spatzle/Toll/cactus controls the potent antifungal response in Drosophila adults. Cell 1996;86:973-83.

10 Selsted ME, Harwig SS. Determination of the disulfide array in the human defensin HNP-2. A covalently cyclized peptide. F Biol Chem 1989;264: 4003-7.

11 Tang Y-Q, Selsted ME. Characterization of the disulfide motif in BNBD-12, an antimicrobial beta-defensin peptide from bovine neutrophils. F Biol Chem 1993;268:6649-53.

12 Zimmermann GR, Legault P, Selsted ME, et al. Solution structure of bovine neutrophil beta-defensin-12: the peptide fold of the beta-defensins is identical to that of the classical defensins. Biochemistry 1995;34:13663-71

13 Sparkes RS, Kronenberg M, Heinzmann C, et al. Assignment of defensin gene(s) to human chromosome 8p23. Genomics 1989;5:240-4.

14 Harder J, Siebert R, Zhang Y, et al. Mapping of the gene encoding human beta-defensin-2 (DEFB2) to chromosome region 8p22-p23.1. Genomics 1997;46:472-5.

15 Liu L, Zhao C, Heng HH, et al. The human beta-defensin-1 and alpha-defensins are encoded by adjacent genes: two peptide families with differing disulfide topology share a common ancestry. Genomics 1997;43: 316-20.

16 Ouellette AJ, Pravtcheva D, Ruddle FH, et al. Localization of the cryptdin locus on mouse chromosome 8. Genomics 1989;5:233-9.

17 Huttner KM, Kozak CA, Bevins CL. The mouse genome encodes a single homolog of the antimicrobial peptide human beta-defensin 1. FEBS Lett homolog of the

18 Morrison GM, Davidson DJ, Kilanowski FM, et al. Mouse beta defensin-1 is a functional homolog of human beta defensin-1. Mamm Genome 1998;9: is a functio 453 .

19 Bals R, Goldman MJ, Wilson JM. Mouse beta-defensin 1 is a salt-sensitive antimicrobial peptide present in epithelia of the lung and urogenital tract. Infect Immun 1998;66:1225-32.

$20 \mathrm{Jia}$ HP, Mills JN, Barahmand-pour F, et al. Molecular cloning and characterization of rat genes encoding homologues of human betadefensins. Infect Immun 1999;67:4827-33.

21 Selsted ME, Brown DM, DeLange RJ, et al. Primary structures of MCP-1 and MCP-2, natural peptide antibiotics of rabbit lung macrophages. $\mathcal{F}$ Biol Chem 1983;258:14485-9.

22 Selsted ME, Harwig SS, Ganz T, et al. Primary structures of three human neutrophil defensins. F Clin Invest 1985;76:1436-9.

23 Ganz T, Selsted ME, Szklarek D, et al. Defensins. Natural peptide antibiotics of human neutrophils. F Clin Invest 1985;76:1427-35.

24 Selsted ME, Miller SI, Henschen AH, et al. Enteric defensins: antibiotic Selsted ME, Miller SI, Henschen AH, et al. Enteric defensins: antibiotic
peptide components of intestine host defense. $\mathcal{F}$ Cell Biol 1992;118:929-36. peptide components of intestine host defense. F Cell Biol 1992;118:929-36.
25 Harwig SS, Eisenhauer PB, Chen NP, et al. Cryptdins: endogenous Harwig SS, Eisenhauer PB, Chen NP, et al. Cryptdins: endogenous
antibiotic peptides of small intestinal Paneth cells. Adv Exp Med Biol 1995; 371A:251-5. 
26 Quayle AJ, Porter EM, Nussbaum AA, et al. Gene expression, immunolocalization and secretion of human defensin- 5 in human female reproduclocalization and secretion of human defensin
tive tract. Am $\mathcal{7}$ Pathol 1998;152:1247-58.

27 Diamond G, Zasloff $M$, Eck H, et al. Tracheal antimicrobial peptide, a novel cysteine-rich peptide from mammalian tracheal mucosa: peptide isolation and cloning of a cDNA. Proc Natl Acad Sci USA 1991;88:3952-6.

28 Diamond G, Bevins CL. $\beta$-defensins: endogenous antibiotics of the innate host defense response. Clin Immunol Immunopathol 1998;88:221-5.

29 Schonwetter BS, Stolzenberg ED, Zasloff MA. Epithelial antibiotics induced at sites of inflammation. Science 1995;267:1645-8.

30 Krisanaprakornkit S, Weinberg A, Perez CN, et al. Expression of the peptide antibiotic human beta-defensin 1 in cultured gingival epithelial cells and gingival tissue. Infect Immun 1998;66:4222-8.

31 Tarver AP, Clark DP, Diamond G, et al. Enteric $\beta$-defensin: molecular cloning and characterization of a gene with inducible intestinal epithelial expression associated with Cryptospiridium parvum expression. Infect Immun 1998;66:1045-56.

32 Shi J, Zhang G, Wu H, et al. Porcine epithelial beta-defensin 1 is expressed in the dorsal tongue at antimicrobial concentrations. Infect Immun 1999;67: 3121-7.

33 Bensch KW, Raida M, Mägert H-J, et al. hBD-1: a novel $\beta$-defensin from human plasma. FEBS Lett 1995;368:331-5.

34 Zhao C, Wang I, Lehrer RI. Widespread expression of beta-defensin hBD-1 in human secretory glands and epithelial cells. FEBS Lett 1996;396:319-

35 Harder J, Bartels J, Christophers E, et al. A peptide antibiotic from human skin. Nature 1997;387:861.

36 Valore EV, Park CH, Quayle AJ, et al. Human $\beta$-defensin-1: An antimicrobial peptide of urogenital tissues. F Clin Ivest 1998;101:1633-42.

37 Selsted ME, Tang Y-Q, Morris WL, et al. Purification, primary structures, and antibacterial activities of beta-defensins, a new family of antimicrobial peptides from bovine neutrophils. F Biol Chem 1993;268:6641-8.

38 Ouellette AJ, Greco RM, James M, et al. Developmental regulation of cryptdin, a corticostatin/defensin precursor mRNA in mouse small intestinal crypt epithelium. F Cell Biol 1989;108:1687-95.

39 Jones DE, Bevins CL. Paneth cells of the human small intestine express an antimicrobial peptide gene. F Biol Chem 1992;267:23216-25.

40 Jones DE, Bevins CL. Defensin-6 mRNA in human Paneth cells: implications for antimicrobial peptides in host defense of the human bowel. FEBS Lett 1993;315:187-92.

41 Ouellette AJ, Hsieh MM, Nosek MT, et al. Mouse Paneth cell defensins: primary structures and antibacterial activities of numerous cryptdin isoforms. Infect Immun 1994;62:5040-7.

42 Mallow EB, Harris A, Salzman N, et al. Human enteric defensins: gene structure and developmental expression. f Biol Chem 1996;271:4038-45.

43 Darmoul D, Ouellette AJ. Positional specificity of defensin gene expression reveals Paneth cell heterogeneity in mouse small intestine. Am $\mathcal{F}$ Physiol 1996;271:G68-74.

44 Ouellette AJ, Miller SI, Henschen AH, et al. Purification and primary structure of murine cryptdin-1, a Paneth cell defensin. FEBS Lett 1992;304: 146-8.

45 Eisenhauer PB, Harwig SSSL, Lehrer RI. Cryptdins: antimicrobial defensins of the murine small intestine. Infect Immun 1992;60:3556-65.

46 Porter E, Liu L, Oren A, et al. Localization of human intestinal defensin 5 in Paneth cell granules. Infect Immun 1997;65:2389-95.

47 Porter E, van Dam E, Valore E, et al. Broad spectrum antimicrobial activity of human intestinal defensin 5. Infect Immun 1997;65:2396-401.

48 Peeters T, Vantrappen G. The Paneth cell: a source of intestinal lysozyme. Gut 1975; 16:553-8.

49 Harwig SSL, Tan L, Qu X-D, et al. Bactericidal properties of murine intestinal phospholipase A2. F Clin Invest 1995;95:603-10.
$50 \mathrm{Qu} \mathrm{XD}$, Lloyd KC, Walsh JH, et al. Secretion of type II phospholipase A2 and cryptdin by rat small intestinal Paneth cells. Infect Immun 1996;64: $5161-5$.

51 Satoh Y. Atropine inhibits the degranulation of Paneth cells in ex-germ-free mice. Cell Tissue Res 1988;253:397-402.

52 Albedi FM, Lorenzetti E, Contini M, et al. Immature Paneth cells in intestinal metaplasia of gastric mucosa. Appl Pathol 1984;2:43-8

53 Symonds DA. Paneth cell metaplasia in diseases of the colon and rectum. Arch Pathol 1974;97:343-7.

54 Bry L, Falk P, Huttner K, et al. Paneth cell differentiation in the developing intestine of normal and transgenic mice. Proc Natl Acad Sci USA 1994;91: 10335-9.

55 Stappenbeck TS, Wong MH, Saam JR, et al. Notes from some crypt watchers: regulation of renewal in the mouse intestinal epithelium. Curr Opin Cell Biol 1998;10:702-9.

56 Ganz T. Biosynthesis of defensins and other antimicrobial peptides. Ciba Foundation Symposium 1994;186:62-76.

57 Bateman A, Singh A, Shustik C, et al. The isolation and identification of multiple forms of the neutrophil granule peptides from human leukemic cells. F Biol Chem 1991;266:7524-30.

58 Harwig SSL, Park ASK, Lehrer RI. Characterization of defensin precursors in mature human neutrophils. Blood 1992;79:1532-7.

59 Valore EV, Ganz T. Posttranslational processing of defensins in immature human myeloid cells. Blood 1992;79:1538-44.

60 Liu L, Ganz T. The pro region of human neutrophil defensin contains a motif that is essential for normal subcellular sorting. Blood 1995;85:1095103.

61 Valore EV, Martin E, Harwig SS, et al. Intramolecular inhibition of human defensin HNP-1 by its propiece. F Clin Invest 1996;97:1624-9.

62 Porter EM, Poles MA, Lee JS, et al. Isolation of human intestinal defensins from ileal neobladder urine. FEBS Lett 1998;434:272-6.

63 Aley SB, Zimmerman M, Hetsko M, et al. Killing of Giardia lambia by cryptdins and cationic neutrophil peptides. Infect Immun 1994;62:5397-403.

64 Singh A, Bateman A, Zhu QZ, et al. Structure of a novel human granulocyte peptide with anti-ACTH activity. Biochem Biophys Res Commun 1988;155: 524-9.

65 MacLeod RJ, Hamilton JR, Bateman A, et al. Corticostatic peptides cause nifedipine-sensitive volume reduction in jejunal villus enterocytes. Proc Natl Acad Sci USA 1991;88:552-6.

66 Chertov O, Michiel DF, Xu L, et al. Identification of defensin-1, defensin-2, and CAP37/azurocidin as T-cell chemoattractant proteins released from interleukin-8-stimulated neutrophils. F Biol Chem 1996;271:2935-40.

67 Higazi AA, Lavi E, Bdeir K, et al. Defensin stimulates the binding of lipoprotein (a) to human vascular endothelial and smooth muscle cells. Blood 1997:89:4290-8.

68 Lencer WI, Cheung G, Strohmeier GR, et al. Induction of epithelial chloride secretion by channel-forming cryptdins 2 and 3. Proc Natl Acad Sci USA 1997;94:8585-9.

69 Lillard JW Jr, Boyaka PN, Chertov O, et al. Mechanisms for induction of acquired host immunity by neutrophil peptide defensins. Proc Natl Acad Sci USA 1999;96:651-6.

70 Garabedian EM, Roberts LJJ, McNevin MS, et al. Examining the role of Paneth cells in the small intestine by lineage ablation in transgenic mice. $\mathcal{F}$ Biol Chem 1997;272:23729-40.

71 Kliegman RM, Fanaroff AA. Necrotizing enterocolitis. N Engl f Med 1984; 310:1093-103.

72 Ballance WA, Dahms BB, Shenker N, et al. Pathology of neonatal necrotizing enterocolitis: a ten year experience. $\mathcal{F}$ Pediatr 1990;117:S6-13.

73 Salzman NH, Polin RA, Harris MC, et al. Enteric defensin expression in necrotizing enterocolitis. Pediatr Res 1998;44:20-6. 